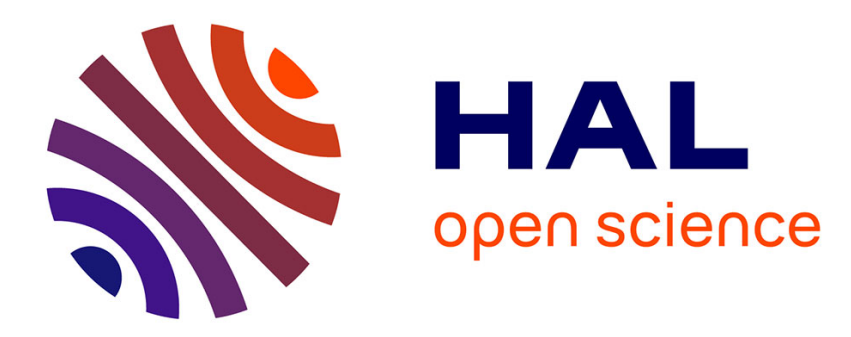

\title{
Finite size arrays of proximity effect bridges
}

\author{
J.L. Berchier, D.H. Sanchez
}

\section{To cite this version:}

J.L. Berchier, D.H. Sanchez. Finite size arrays of proximity effect bridges. Revue de Physique Appliquée, 1979, 14 (8), pp.757-761. 10.1051/rphysap:01979001408075700 . jpa-00244657

\section{HAL Id: jpa-00244657 https://hal.science/jpa-00244657}

Submitted on 1 Jan 1979

HAL is a multi-disciplinary open access archive for the deposit and dissemination of scientific research documents, whether they are published or not. The documents may come from teaching and research institutions in France or abroad, or from public or private research centers.
L'archive ouverte pluridisciplinaire HAL, est destinée au dépôt et à la diffusion de documents scientifiques de niveau recherche, publiés ou non, émanant des établissements d'enseignement et de recherche français ou étrangers, des laboratoires publics ou privés. 


\title{
Finite size arrays of proximity effect bridges $\left({ }^{*}\right)$
}

\author{
J. L. Berchier and D. H. Sanchez \\ Département de Physique de la Matière Condensée, Université de Genève, 32, bd d'Yvoy, 1211 Genève 4, Suisse
}

(Reçu le 23 février 1979, révisé le 25 avril 1979, accepté le 4 mai 1979)

\begin{abstract}
Résumé. - Nous avons étudié des réseaux $20 \times 20$ bidimensionnels de jonctions à effet de proximité en Au/In. La résistance statique à l'origine en fonction de la température montre une transition à $T_{\mathrm{c}}$ (In) et une autre à $T_{\mathrm{c}}^{*}$, inférieure à $T_{\mathrm{c}}(\mathrm{In})$, mais supérieure à $T_{\mathrm{c}}(\mathrm{Au} / \mathrm{In})$. A $T_{c}^{*}$, le système passe dans un état où il n'y a plus de résistance même s'il est composé de jonctions SNS. Chaque région de température est caractérisée par différentes formes de courbes courant-tension.
\end{abstract}

\begin{abstract}
We have studied devices consisting of $20 \times 20$ two dimensional arrays of proximity effect junctions of $\mathrm{Au} / \mathrm{In}$. The DC resistance at the origin as a function of temperature shows a transition at $T_{\mathrm{c}}$ (In) and another one at $T_{\mathrm{c}}^{*}$, below $T_{\mathrm{c}}(\mathrm{In})$ but above $T_{\mathrm{c}}(\mathrm{Au} / \mathrm{In})$. At $T_{\mathrm{c}}^{*}$ the devices go into a resistanceless state even though they are composed of SNS junctions. Different shapes of the current-voltage curves characterize each temperature region.
\end{abstract}

1. Introduction. - In the last years attention was paid to interaction between individual junctions that show themselves Josephson type effects. Rosenblatt and coworkers [1] worked on a possible collective interaction that may appear in a lattice of junctions made of spheres of $\mathrm{Nb}$ pressed together. They proposed that the weak Josephson coupling between $\mathrm{Nb}$ spheres gives rise to a sort of dynamic phase transition from a state of phase disorder to a state of phase coherence at a temperature $T_{\mathrm{c}}^{*}$ lower than $T_{\mathrm{c}}(\mathrm{Nb})$.

Work done on granular films of $\mathrm{NbN}$ [2] and AlGe [3] may also be interpreted as evidence of a phase transition occurring well below $T_{\mathrm{cG}}$ of each grain. Gubser and Wolf [2] explained their results as a transition from a phase incoherent state to a coherent one coming from Josephson coupling between grains. The problem has been recently studied theoretically by Barnes [4] and by Giovannini and Weiss [5]. The main inconvenience with pressed spheres and granular films consists in the irregularity of the lattice formed by those systems.

More regular one dimensional lattices were done by either proximity effect bridges [6] or lamellar eutectic alloys [7]. The goal of those experiments was mainly the study of the transport properties of the samples themselves. The analyses were done based on the de Gennes' model [8] for the dirty limit and the Kulik's model [9] for the clean limit. Dupart et al. [10] made a one dimension band structure

(*) Supported by the Swiss National Science Foundation. calculation, using the Kulik's model to describe a single junction, to account for their observations in the $\mathrm{Pb}-\mathrm{Sn}$ eutectic alloy. A recent paper by Spencer et al. [7] on $\mathrm{Pb}-\mathrm{Cd}$ laminar eutectics shows the complexity of the behaviour of these samples, where flux pinning and flux flow are reported to show up in the transport properties.

With the aim of studying possible collective effects coming from Josephson coupling we investigated finite two dimensional arrays of proximity effect bridges made of $\mathrm{Au} / \mathrm{In}$. We report here results concerning the properties of arrays composed of $20 \times 20$ squares of In separated by $\mathrm{Au} / \mathrm{In}$.

2. Experimental. - The samples were made by application of a projection photolithographic technique developed by us [11]. A film of $230 \AA$ of gold is evaporated on a sapphire substrate. A coat of photoresist (P.R.) AZ-1350 is applied on it and a mask having the design of figure $1 a$ projected. The unprotected regions of the film are chemically etched with a solution composed of

$$
\begin{aligned}
& 1 \text { part of a mixture made of } \\
& 400 \mathrm{~g} \mathrm{KI} \\
& 100 \mathrm{~g} \mathrm{I}_{2} \\
& 400 \mathrm{ml} \text { distilled } \mathrm{H}_{2} \mathrm{O} \\
& 40 \text { parts distilled } \mathrm{H}_{2} \mathrm{O} \text {. }
\end{aligned}
$$

This leaves in the middle of the substrate a film of gold having the replica of the mask reduced by a factor given by the objective chosen $(16 \times$ or $40 \times)$. After 


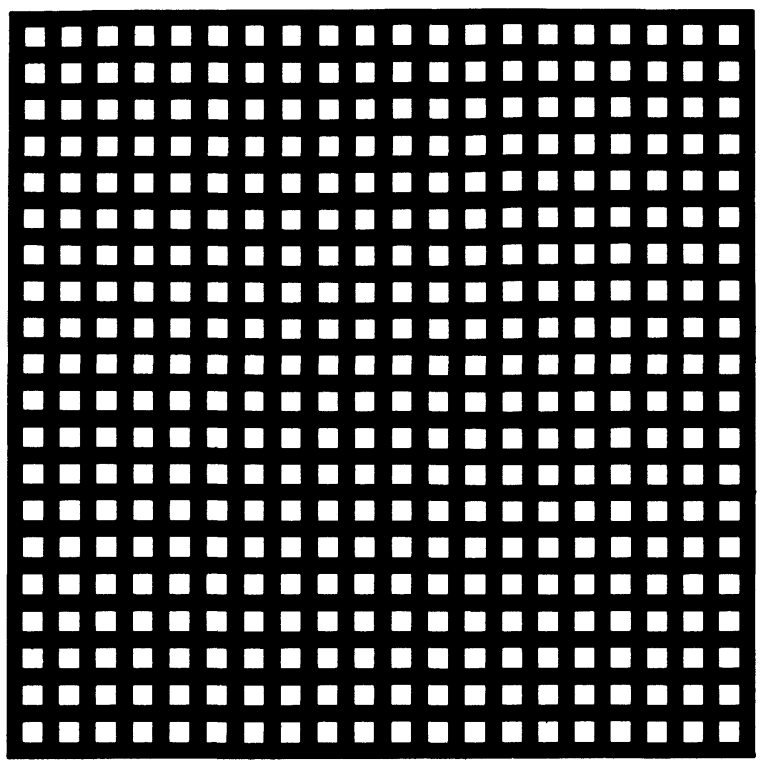

a)

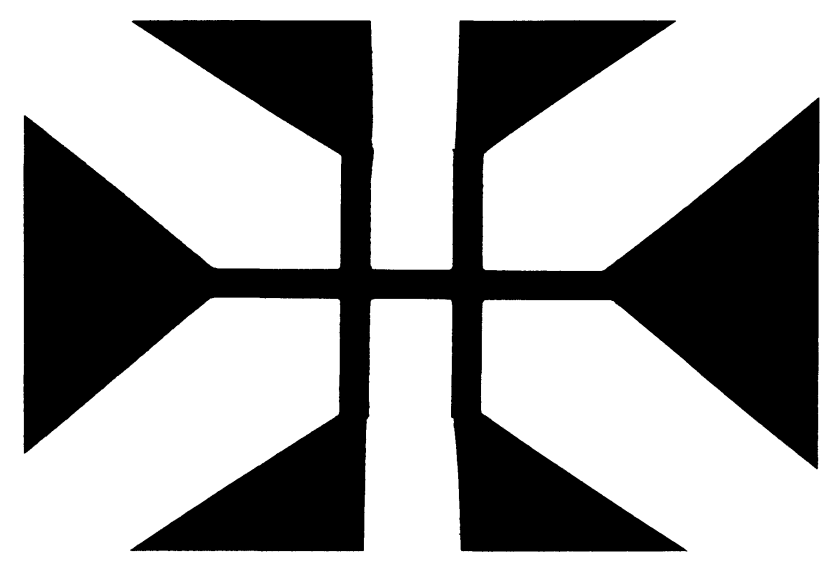

b)

Fig. 1. - a) Mask projected onto the Au film. The blacks correspond to the regions that will stay after etching of the Au film and will become the $\mathrm{Au} / \mathrm{In}$ regions when the In film is evaporated. The whites are the regions unprotected by the photoresist and etched away in the Au film. They become the In squares when the second evaporation is made. $b$ ) Mask projected onto the In film that covers the Au design. The blacks are the protected regions and the whites

removing the P.R. with pure acetone a second evaporation is made of $500 \AA$ of In. The samples are recoated with P.R. and the mask shown in figure $1 b$ projected with an objective $4 \times$. The unprotected regions are chemically etched with a solution composed of

$$
\begin{aligned}
& 2 \text { parts } \mathrm{NO}_{3} \mathrm{H}(67 \%) \\
& 1 \text { part } \mathrm{ClH}(32 \%) \\
& 6 \text { parts distilled } \mathrm{H}_{2} \mathrm{O} \text {. }
\end{aligned}
$$

The resulting sample is shown in figure $1 c$ for a reduction $16 \times$. In figure $1 d$ we give the dimensions for the R16G and R40G, which are the two examples that we want to discuss here.

The mean free path for each material was measured in films evaporated simultaneously with the samples.

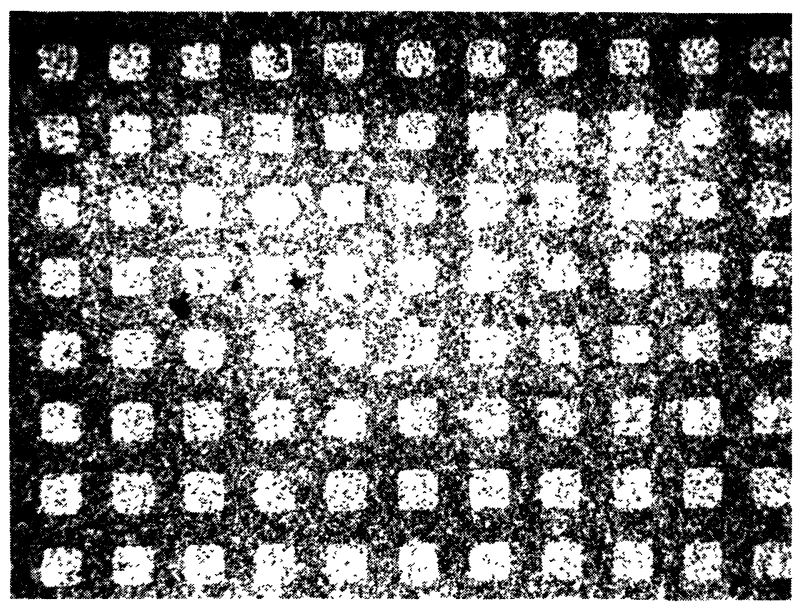

c)
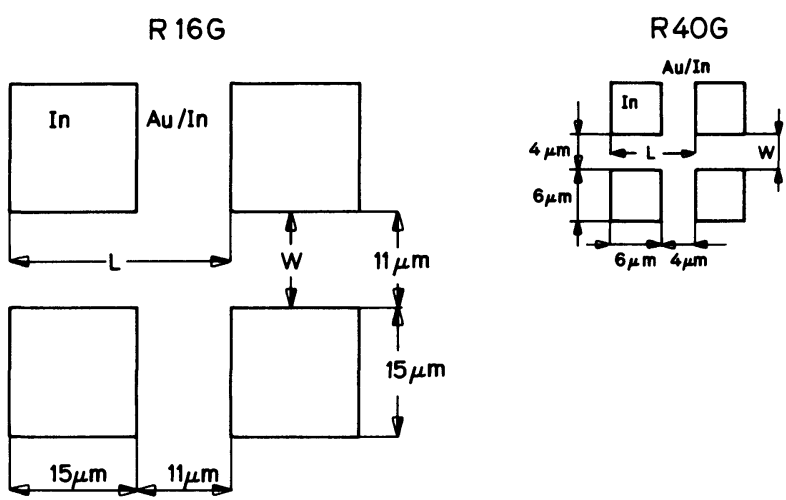

d)

the regions to be etched. There are two horizontal contacts for the current, and four vertical ones for the voltage. The array is placed in the middle. c) Photograph made of the $R 16 \mathrm{G}$ sample $(400 \times)$ after repeated recycling between low and room temperature. d) Schematic drawing showing the dimensions of the arrays presented in this work.

For the film of gold we got $l$ FILM $(\mathrm{Au}) \approx 0.04 \mu \mathrm{m}$ and for the indium $l$ FILM $(\mathrm{In}) \approx 0.6 \mu \mathrm{m}$.

The devices were mounted inside a variable temperature cryostat and four terminal resistance and current-voltage $(I-V)$ measurements done [12].

3. Results. - In figure $2 a$ we show the variation of the DC resistance at the origin as a function of temperature for the R16G sample. One can observe that there are two different transitions, one occurring at about $T_{\mathrm{c}}$ (In) and another one occurring at a lower temperature $T_{\mathrm{c}}^{*}$. This second $T_{\mathrm{c}}^{*}$ is found to be at a higher $T$ than the one expected for the regions $\mathrm{Au} / \mathrm{In}$. In figure $2 b$ we show the variation of the $\mathrm{DC}$ resistance 


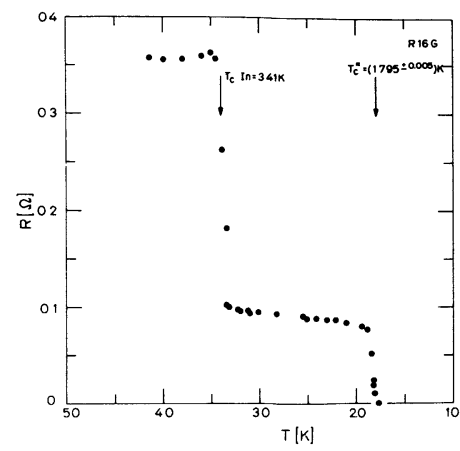

a)

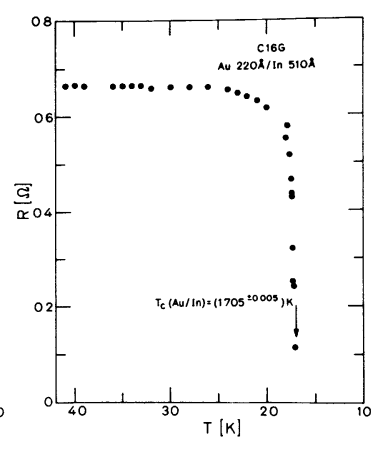

b)
Fig. 2. $-a$ ) The DC resistance at the origin as a function of temperature showing the transitions at $T_{\mathrm{c}}$ (In) and $T_{\mathrm{c}}^{*}$ for the R16G sample. The results are similar for the R40G. b) Idem for the sandwich Au $220 \AA / \operatorname{In} 510 \AA$

at the origin of a sandwich of $\mathrm{Au}(220 \AA) / \operatorname{In}(510 \AA)$ (sample C16G).

We were able to determine $T_{\mathrm{c}}^{*}$ within $0.005 \mathrm{~K}$ from the critical current $I_{\mathrm{c}} v$ s. $T$ curves (Fig. 3) which corresponds to an $I_{\mathrm{c}}<0.5 \mu \mathrm{A}$. These results show clearly two things. First $T_{\text {cau/nn }}(\mathrm{C} 16 \mathrm{G})=1.705 \mathrm{~K}$ is below $T_{\mathrm{c}}^{*}(\mathrm{R} 16 \mathrm{G})=1.795 \mathrm{~K}$ and $T_{\mathrm{c}}^{*}(\mathrm{R} 40 \mathrm{G})=1.820 \mathrm{~K}$. Second, $T_{\mathrm{c}}^{*}(\mathrm{R} 40 \mathrm{G})$, the array for which the distance between In squares is shorter, occurs at a higher $T$

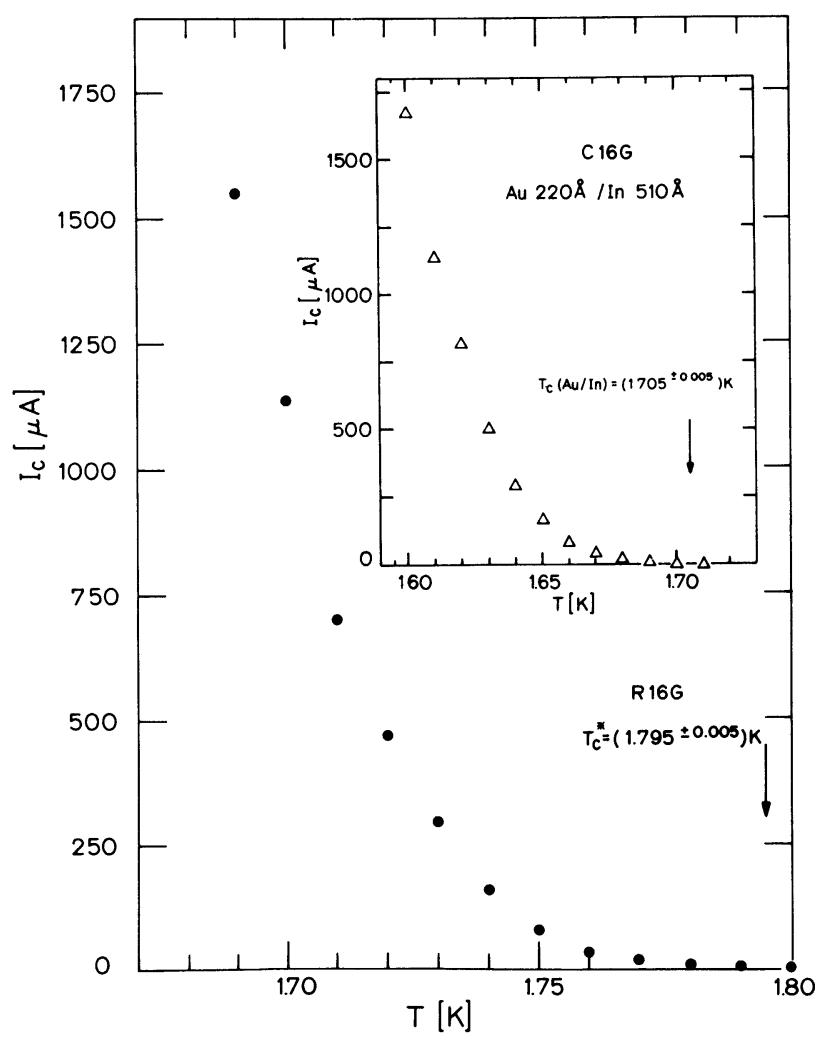

Fig. 3. - Variation of the critical current $I_{\mathrm{c}}$ versus temperature for the R16G sample. The results are similar for the R40G sample. The insert shows the situation for the $\operatorname{san} \varphi$ wich $\mathrm{Au} / \mathrm{In}$. than that of $T_{\mathrm{c}}^{*}(\mathrm{R} 16 \mathrm{G})$, the array for which the separation is larger.

These observations imply that the arrays go into a resistanceless state at a temperature $T_{\mathrm{c}}^{*}$ before the $\mathrm{Au} / \mathrm{In}$ regions become superconducting. The shorter the separation distance between In squares the higher $T_{\mathrm{c}}^{*}$.

In figure 4 we show the $V-I$ characteristics as a function of temperature. Below $T_{\mathrm{c}}(\mathrm{In})$ the $V-I$ curves are ohmic with reducing slope. When the jump in $T_{\mathrm{c}}^{*}$ starts the characteristics are ohmic only very near the origin. Finally below $T_{\mathrm{c}}^{*}$ a resistanceless state is observed giving the $V-I$ curves shown in figure $4 a$ for the R16G sample.

When $T_{\mathrm{c}}(\mathrm{Au} / \mathrm{In})$ is approached, the $V$-I curves for the R40G sample show a different behaviour (Fig. 4b). We believe the same happens with the R16G but it was outside the range of our equipment to measure its $V-I$ characteristic lower than $1.68 \mathrm{~K}$ due to the fast increase of $I_{\mathrm{c}}$ with lowering $T$ for a sample of those dimensions.

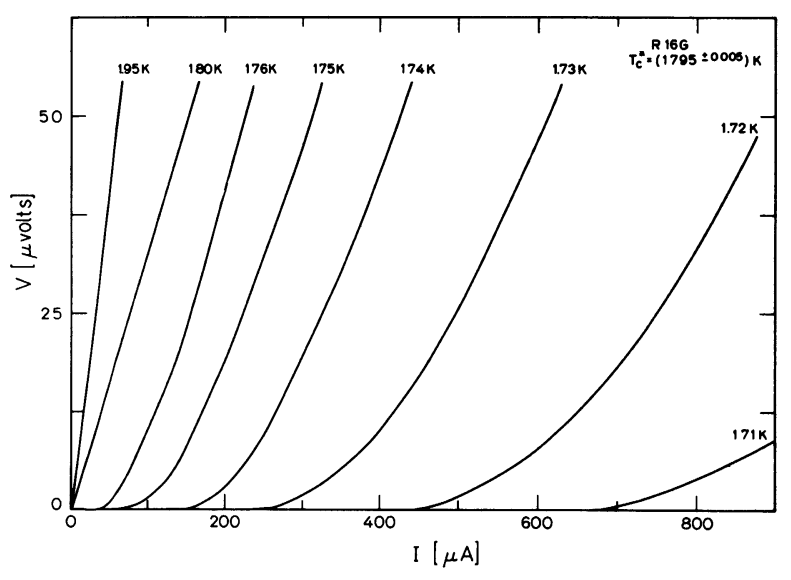

a)

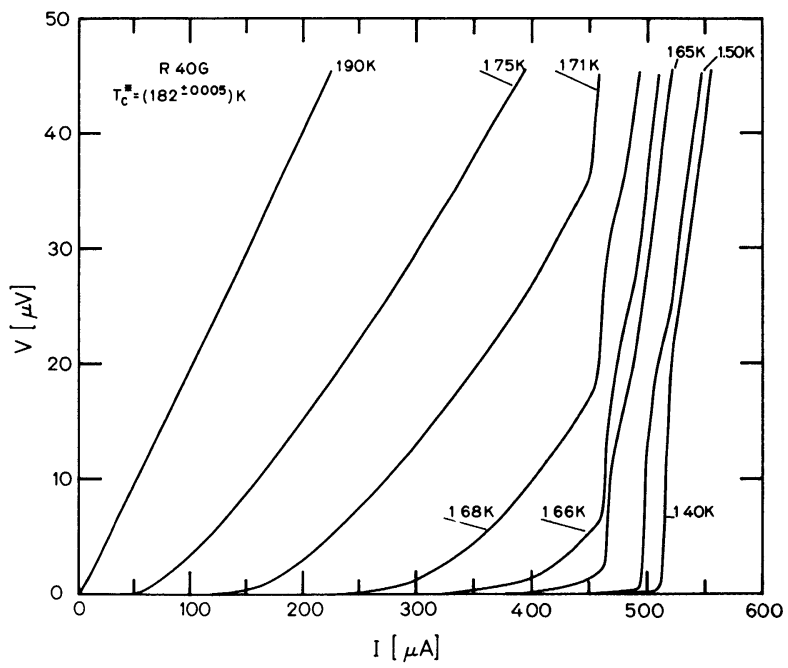

b)

Fig. 4. - a) Voltage versus current for different temperatures sample R16G. b) Idem sample R40G. Notice the change in the $V$ scale and the different behaviour below $T_{\mathrm{c}}(\mathrm{Au} / \mathrm{In})$. 
4. Discussion. - We will discuss first the way the DC resistance $R$ at the origin approaches $T_{\mathrm{c}}^{*}$. Our results resemble those of Gubser and Wolf [2] where the $V=V(I, T)$ curves are described by an expression based on scaling laws of critical phenomena suggested to them by Pr. Y. Imry.

We found that our $R$ vs. $T$ curves can be described within $10 \%$ error when $T \rightarrow T_{\mathrm{c}}^{*}$ by the formula

$$
R=R_{\mathrm{a}} \frac{L}{W}\left(\frac{T-T_{\mathrm{c}}^{*}}{T_{\mathrm{c}}^{*}}\right)^{\alpha} \quad\left(T>T_{\mathrm{c}}^{*}\right)
$$

where $R_{\mathrm{a}}$ is a square resistance equal to $0.82 \Omega, L$ is the length and $W$ the width of a section of the $\mathrm{Au} / \mathrm{In}$ region shown in figure $1 d$, and $\alpha$ a critical exponent equal to $(0.85 \pm 0.15)$. In a similar way the $V-I$ curve for $T=T_{\mathrm{c}}^{*}$ can be described by a relation of the type

$$
V=A L\left(\frac{I}{W}\right)^{\beta} \quad\left(T=T_{\mathrm{c}}^{*}\right)
$$

where $V$ is measured in $\mu \mathrm{V}, I$ in $\mu \mathrm{A}, A$ is a constant equal to $0.011[(\mu \mathrm{V} / \mu \mathrm{m})] /\left[(\mu \mathrm{A} / \mu \mathrm{m})^{\beta}\right]$, and $\beta$ a second critical exponent equal to $(1.58 \pm 0.30)$.

Equations (1) and (2) are particular cases of a more general expression that describes the $V$ - $I$ characteristics above $T_{\mathrm{c}}^{*}$

$$
V=B I^{\beta} \chi\left(\frac{\Delta T}{I^{\gamma}}\right) \quad\left(T>T_{\mathrm{c}}^{*}\right)
$$
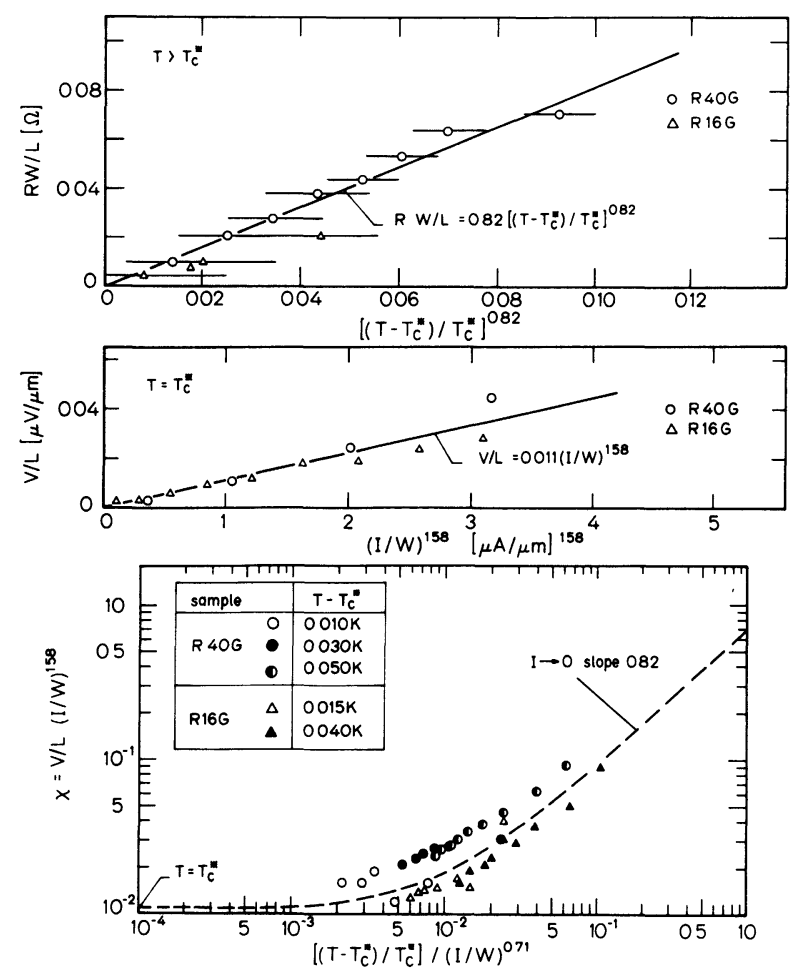

Fig. 5. - Gubser and Wolf's [2] type analysis of the approaching to $T_{\mathrm{c}}^{*}$ of the DC resistance at the origin (top); voltage versus current at $T=T_{\mathrm{c}}^{*}$ (middle); and $\chi$ function plotting for different $\left(T-T_{\mathrm{c}}^{*}\right)$ above $T_{\mathrm{c}}^{*}$ (bottom). where $\chi$ is a function having the specific limits [2]

$$
\begin{aligned}
I \rightarrow 0 & \chi \rightarrow\left(\frac{\Delta T}{I^{\gamma}}\right)^{\alpha} \\
\left(T-T_{\mathrm{c}}^{*}\right) \rightarrow 0 & \chi \rightarrow 1
\end{aligned}
$$

and $\gamma$, the third critical exponent, is found to be equal to $(\beta-1) / \alpha=(0.71 \pm 0.30)$. The results of this type of analysis are shown in figure 5 , where one sees that in fact the data show a clear tendency to fall into an universal curve. We want to remark that the determination of $\alpha, \beta$ and $\gamma$, can be made with a much higher precision for each sample. But at present we preferred an overall view giving the general tendencies on the way the transition $T_{\mathrm{c}}^{*}$ is approached from above.

In the temperature region between $T_{\mathrm{c}}^{*}$ and $T_{\mathrm{c}}(\mathrm{Au} / \mathrm{In})$ our samples are formed by SNS junctions, that can be considered as being in the clean limit ( $($ FILM $($ In $)=0.6 \mu \mathrm{m})$. In fact attempts to fit de Gennes' theory proved unsuccessful.

Bardeen-Johnson (BJ) $[9,10]$ calculated the variation of the critical current $J_{\mathrm{c}}$ as a function of $T$. Their result well below $T_{\mathrm{c}}$ (In) can be written as

$$
J_{\mathrm{c}}=J_{0} \exp -\left[2 d^{*} k_{\mathrm{B}} / \xi_{0} \Delta(T=0)\right] T
$$

where

$$
J_{0}=6 n_{\mathrm{e}} \hbar e / m d^{*}
$$

and the distance $d^{*}=d_{\mathrm{N}}+\pi \xi_{0}$, where $d_{\mathrm{N}}$ is the width of the normal region ( $\mathrm{Au} / \mathrm{In})$ between two In squares. When the temperature dependence of the gap is taken into account [10], $d^{*}$ is given by

$$
d_{\mathrm{N}}+\pi \xi_{0}[\Delta(T=0) / \Delta(T)]
$$

and the BJ expression (Equations (5) and (6)) is still valid. Using the values of $[\Delta(T=0) / \Delta(T)]$ for a BCS superconductor [13] it is possible to show that the correction is small in our case.

Figure 6 shows a plot of $I_{\mathrm{c}}$ versus $T$ for both samples, together with the BJ prediction for 20 single junctions in parallel calculated using equation (5) and [14] $\xi_{0}($ In $)=2600 \AA, \Delta(0)=1.82 k_{\mathrm{B}} T_{\mathrm{c}}$ (In); $T_{\mathrm{c}}(\mathrm{In})=3.407 \mathrm{~K}$ and $n_{\mathrm{e}}=11.5 \times 10^{28}$ electrons $/ \mathrm{m}^{3}$.

It can be graphically seen that the experimental results do not follow the $\mathrm{BJ}$ temperature dependence prediction near $T_{\mathrm{c}}^{*}$, and for the R16G one observes a larger current than allowed by BJ while for the R40G is smaller. Well below $T_{\mathrm{c}}^{*}$ our data could be fitted to $I_{0} \exp (-\beta T)$ : with $\beta$ (fit) $>\beta$ (BJ). This has been interpreted in linear arrays [6] as coming from the fact that $l$ (FILM) $<d_{\mathrm{N}}$, which is the case of our samples. The BJ theory applies only to situations where $\ell$ (FILM) $>d_{\mathrm{N}}$, and $\beta$ and $J_{0}$ (Eq. (6)) may change otherwise. But we should remark that near $T_{c}^{*}$ we observe deviations from an exponential fitting. 


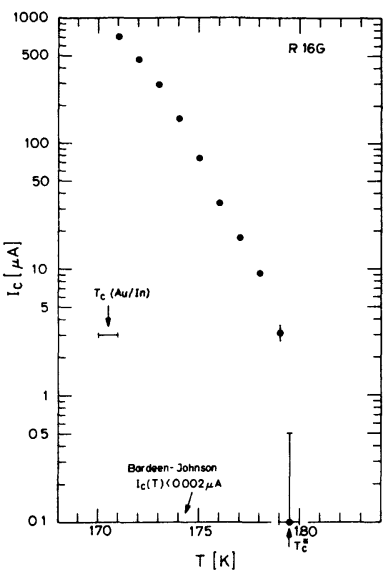

a)

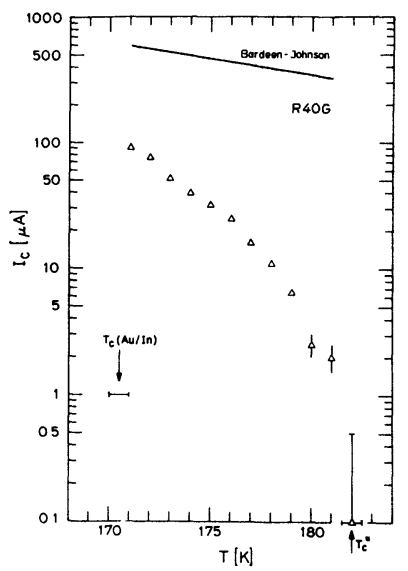

b)
Fig. 6. - - a) Variation of the critical current versus temperature between $T_{\mathrm{c}}^{*}$ and $T_{\mathrm{c}}(\mathrm{Au} / \mathrm{In})$ for the $\mathrm{R} 16 \mathrm{G}$ sample. $b$ ) Idem for the R40G sample where the solid line shows the prediction of 20 parallel junctions that follow Bardeen Johnson theory.

5. Conclusions. - We have shown the $V-I$ characteristics of $20 \times 20$ lattices of proximity effect bridges. These samples show two different transition temperatures in their DC resistance at the origin vs. temperature curve, one occurring at $T_{\mathrm{c}}(\mathrm{In})$ and the other at $T_{\mathrm{c}}^{*}$ above $T_{\mathrm{c}}(\mathrm{Au} / \mathrm{In})$. Below $T_{\mathrm{c}}^{*}$ the samples go into a resistanceless state and are composed of a lattice of SNS junctions. Each temperature region is characterized by a particular shape of the $V-I$ curve. These curves resemble those of granular films permitting us to make the same type of formal analysis as Gubser and Wolf [2] did for their NbN films [15].
But the resemblance cannot be pushed further at the moment unless a theory valid for proximity effect bridges is constructed.

The examples shown in this work look to us as the best to present the general features of the temperature behaviour. But perhaps it will be convenient to recall that $T_{\mathrm{c}}^{*}$ can be changed also by changing the thickness of the films. For example a $40 \times$ sample made on a film of $240 \AA$ of gold and $650 \AA$ of indium shows a transition at $T_{\mathrm{c}}^{*}=3.25 \mathrm{~K}$, while a sandwich of $\mathrm{Au} / \mathrm{In}$ made simultaneously shows a single transition at $T_{\mathrm{c}}(\mathrm{Au} / \mathrm{In})=1.62 \mathrm{~K}$. This sample has similar $V-I$ curves for each temperature region as the ones discussed in this work. We believe this is a good example to discourage the idea that $T_{c}^{*}$ is simply an enhancement of $T_{\mathrm{c}}(\mathrm{Au} / \mathrm{In})$.

At present we do not have any solid idea to explain the $I_{\mathrm{c}} v s . T$ results. The possibility of a transition from a state of phase disorder to one of phase order, even though it is an appealing one, is not proved for the moment. The theoretical approach of Barnes [4] applies specifically to granular films and should be generalized to SNS junction's if any serious attempt to test it with our results is made. On the other hand the treatment of Giovannini and Weiss [5] is the subject of our present research.

Acknowledgments. - We would like to thank Prof. B. Giovannini for suggesting this work and for many clarifying discussions. The invaluable help of Mr. R. Cartoni whose aid in every stage of this research has been of the utmost importance is greatefully acknowledged.

\section{References}

[1] Rosenblatt, J., Revue Phys. Appl. 9 (1974) 217, and references cited therein.

[2] Gubser, D. U. and Wolf, S. A., J. Physique Colloq. 39 (1978) C6-579 (presented at the LT XV, Grenoble, 1978).

[3] Deutscher, G. and Rappaport, M. L., J. Physique Colloq. 39 (1978) C6-581 (presented at the LT XV, Grenoble, 1978)

[4] Barnes, S. E., Phys. Lett. 66A (1978) 422.

[5] Giovannin,, B. and Weiss, L., Solid State Commun. 28 (1978) 1005.

[6] Palmer, D. W. and Mercereau, J. E., IEEe Trans. Magn. MAG 11 (1975) 667.

Romagnan, J. P., Gilabert, A., Laheurte, J. P., Noiray, J. C. and GuYon, E., Solid State Commun. 16 (1975) 359.

[7] Dupart, J. M. and BayXeras, J., Appl. Phys. Lett. 30 (1977) 123.

Spencer, C. R., Martinoli, P., Gibson, E. D., Verhoeven, J. D. and FinNemore, D. K., Phys. Rev. B 18 (1978) 1216.

[8] Gilabert, A., Ann. Phys. 2 (1977) 203.

De Gennes, P. G., Rev. Mod. Phys. 36 (1964) 225.
[9] KulIK, I. O., Zh. Eksp. Teor. Fiz. 57 (1969) 1745. (English Translation : Sov. Phys. JETP 30 (1970) 944.)

Bardeen, J. and Johnson, J. L., Phys. Rev. B 5 (1972) 72.

[10] Dupart, J. M., Rosenblatt, J. and Baixeras, J., Phys. Rev. B 16 (1977) 4815.

[11] BerchieR, J. L. and SANChez, D. H., Rev. Sci. Instrum. 49 (1978) 1452.

[12] To be published.

[13] Ramos, E. D. and Sanchez, D. H., Cryogenics 14 (1974) 341.

[14] Cunha Belo, M., Monographies sur les métaux de haute pureté (Ed. Masson \& Cie) Vol. 1 (1972), chap. 21.

[15] Wolf et al., Phys. Rev. Lett. 42 (1979) 324, obtain the following critical exponents $\mu=3.9 \pm 0.3$ (as compared to our $\alpha=0.85 \pm 0.15) ; \quad \lambda=0.5 \quad(\gamma=0.71 \pm 0.30)$ and $v=3.0 \pm 0.2(\beta=1.58 \pm 0.30)$. The exponent $\alpha$ (or $\mu)$ is related to the critical index $z$, which is difficult to calculate accurately for two dimensional systems. Preliminary calculations yield $\alpha$ (or $\mu) \simeq 1$ (B. Giovannini, private communication). 